\title{
Analysis of attempted suicide episodes presenting to the emergency department: comparison of young, middle aged and older people
}

\author{
Soo Hyun Kim ${ }^{1}$, Han Joon $\mathrm{Kim}^{2 *}$, Sang Hoon $\mathrm{Oh}^{2}$ and Kyungman Cha ${ }^{3}$
}

\begin{abstract}
Background: Attempted suicide remains difficult for clinicians to predict with some established risk factors. We investigate the detailed characteristics of attempted suicide especially according to age and methods of suicide attempts.

Methods: A retrospective study was conducted to evaluate patients who visited the emergency department due to attempted suicide. A retrospective medical record review of all patients who presented to the emergency department (ED) of two tertiary teaching hospitals in Korea after suicide attempt between January 1, 2010, and December 31, 2017 was performed. Demographic information and detailed variables (methods and reasons of suicide attempts and variables regarding reattempts) were investigated. Total participants were classified into 3 groups according to age, young group, middle aged group and the older group, and each characteristics were compared.
\end{abstract}

Results: A total of 3698 patients were enrolled in this study. Deliberate self-poisoning (DSP) was the most common method of attempted suicide (66.5\%) followed by cutting (24.4\%), hanging (7.9\%), falling (2.6\%), and drowning (1.1\%). In patients who had previous suicide attempts $(n=1029,27.8 \%)$, attempted methods were likely to be concordant with previous attempted methods. The most common reason for suicide attempts was interpersonal relationship issues followed by socio-economic reasons. Older patients $(n=412,11.2 \%)$ were significantly different from other 2 groups ( $n=3286,88.8 \%$ ) regarding gender, suicide re-attempt, occupation, alcohol co-ingestion, previous psychiatric history, and discharge outcomes (all p-values $<0.001$ ). Especially, in older patients, use of critical method and reason of physical illness were more common.

Conclusion: Our findings indicated that people who attempted suicide might have different sociodemographic and clinical factors depending on age group. Depending on age, it is necessary to apply additional suicide intervention programs in different ways.

Keywords: Attempted suicide, Older adults, Young adults

\footnotetext{
*Correspondence: hanjoon@catholic.ac.kr

${ }^{2}$ Department of Emergency Medicine, Seoul St. Mary's Hospital,

College of Medicine, The Catholic University of Korea, 222 Banpo-daero, Seocho-gu, Seoul 06591, Republic of Korea

Full list of author information is available at the end of the article
}

\section{Background}

Every 40 s, a person dies by suicide somewhere in the world. Suicide kills approximately 800,000 people in a year, accounting for approximately $1.4 \%$ of all deaths worldwide [1]. A significantly high suicide rate has been reported in South Korea compared with other countries for several years [2]. The suicide rate in South Korea is

c) The Author(s) 2020. This article is licensed under a Creative Commons Attribution 4.0 International License, which permits use, sharing, adaptation, distribution and reproduction in any medium or format, as long as you give appropriate credit to the original author(s) and the source, provide a link to the Creative Commons licence, and indicate if changes were made. The images or other third party material in this article are included in the article's Creative Commons licence, unless indicated otherwise in a credit line to the material. If material is not included in the article's Creative Commons licence and your intended use is not permitted by statutory regulation or exceeds the permitted use, you will need to obtain permission directly from the copyright holder. To view a copy of this licence, visit http://creativeco mmons.org/licenses/by/4.0/. The Creative Commons Public Domain Dedication waiver (http://creativecommons.org/publicdomain/ zero/1.0/) applies to the data made available in this article, unless otherwise stated in a credit line to the data. 
the second highest among the Organization for Economic Co-Operation and Development (OECD) member countries at 25.8 deaths per 100,000 people, which is approximately 2.2 times higher than the OECD average of 11.6 deaths per 100,000 people [3]. Thus, suicide prevention is a major public health issue in South Korea. Although national approaches are being taken to prevent suicide, suicide rates are steadily increasing. In addition, the suicide rate of the older population in South Korea is the highest among the 34 OECD countries [4]. South Korea is now entering a rapidly aging society, and the older population is expected to increase to $20.8 \%$ by 2026 [5]. Therefore, the high suicide rate among older adults has become an alarming public health issue in South Korea.

Many studies have focused on suicide prevention, but it is impossible to determine the most effective suicide prevention method. However, most researchers have identified methods to prevent suicide, and targeting people who attempted suicide and helping them avoid repeated attempts are considered to be the most effective management strategies. Attempted suicide is the most powerful known risk factor for completed suicide [6-8]. According to a Swedish study, the rate of suicide among individuals in the year after a suicide attempt was approximately 100fold higher than the corresponding suicide rate among age-and sex-matched community control individuals [9]. During the first year after a suicide attempt, the risk for completed suicide varies from 0.8 to $3.0 \%$ for men and from 0.3 to $1.9 \%$ for women [7, 9-11]. Although common risk factors for suicidal behavior have been identified, there are no factors to accurately predict who will be involved in or die from suicidal behavior [12,13].

In the present study, we focused on the epidemiological and socio-environmental factors that lead to attempted suicide. The main aim of this study was to investigate the potential risk factors associated with attempted suicide and the characteristics of patients based on age group. Our results could help to develop and refine strategies for preventing further suicide attempts and completed suicides.

\section{Materials and methods}

We retrospectively reviewed the medical records of attempted suicide patients who were treated at emergency departments (ED) of two sister hospitals between January 1, 2010 and December 31, 2017.

In South Korea, patient information on the cause of ED admission is immediately reported to the National Emergency Department Information System (NEDIS) records. If the cause of admission was deliberate self-harm, information on the method used for each attempted suicide was recorded as either poisoning, cutting or piercing, suffocation, hanging or choking, drowning or near drowning, using fire or heat, falling or jumping from a great height, other method, or unknown. All patients who had visited our ED after attempted suicides were included in the NEDIS records. To reduce missing data, we have supplemented as much data as possible through post management, outpatient clinic, consultation, and reviewing medical records.

We included all patients who presented with objective evidence of a suicide attempt, and we excluded patients who did not present with objective evidence of a suicide attempt. We assessed the patients' age, gender, history of suicide attempts, time interval between past suicide attempts, occupation, living condition (with or without family), alcohol co-ingestion, previous psychiatric history, reason for the suicide attempts and outcome. Additionally, patients who had previously attempted suicide were investigated to determine the previously selected method. When two or more methods were used as suicide attempts, duplication was investigated. In addition, if two or more reasons for suicide attempts were noted, duplication was investigated. Two emergency physicians independently reviewed the medical service records, medical records and psychiatric records. Any discrepancies were arbitrated by a third investigator.

In the present study, the overall characteristics of patients who attempted suicide and the differences between young adults and the older were investigated. In addition, we investigated the time from the first suicide attempt to the re-attempt for patients who reattempted suicide.

The distribution of patient characteristics is presented as either a percentage or the mean \pm standard deviation. To compare the distribution of the characteristics between the two groups, we performed Student's t-tests to analyze continuous variables and Chi squared tests to analyze categorical variables. All statistical analyses were performed using SPSS 16 (SPSS, Chicago, IL), and differences with a p-value $<0.05$ were considered statistically significant. Especially for predicting re-attempt associated factor, logistic regression analysis was performed. all variables with a significance level of $\mathrm{p}<0.05$ in the univariate analysis were included in a multivariable logistic regression model, and the odds ratios (ORs) and 95\% confidence intervals (CIs) were estimated.

The institutional review board of The Catholic University of Korea, Seoul Saint Mary's Hospital approved the study protocols prior to data analysis. Informed consent was waived given the retrospective nature of the study. 


\section{Results}

During the study period, 3698 attempted suicide patients were admitted to the ED, constituting $0.34 \%$ of all ED visits. The characteristics of the patients are shown in Table 1. Of these patients, $1266(34.2 \%)$ were male and $2432(65.8 \%)$ were female. The mean age of the patients was $42.1 \pm 16.6$ years. Among the patients who attempted suicide, twenties were the most. And the younger, the higher the proportion of female among those who attempted suicide, and the older, the higher the proportion of male (Fig. 1). The most common method of attempted suicide was deliberate self-poisoning (DSP) (66.5\%), followed by cutting (24.4\%), hanging (7.9\%), falling $(2.6 \%)$, and drowning (1.1\%). In Fig. 2, we investigate the methods in which suicide attempts were made Table 1 Prevalence of attempted suicide
by sociodemographic and clinical variable $(n=3698)$

\begin{tabular}{|c|c|c|}
\hline & $\mathrm{n}$ & $\%$ \\
\hline \multicolumn{3}{|l|}{ Gender } \\
\hline Male & 1266 & 34.2 \\
\hline Female & 2432 & 65.8 \\
\hline Age, mean $\pm S D$, years & $42.1 \pm 16.6$ & \\
\hline-19 & 97 & 2.6 \\
\hline $20-29$ & 901 & 24.4 \\
\hline $30-39$ & 806 & 21.8 \\
\hline $40-49$ & 807 & 21.8 \\
\hline $50-59$ & 532 & 14.4 \\
\hline $60-69$ & 245 & 6.6 \\
\hline 70-79 & 201 & 5.4 \\
\hline $80-$ & 109 & 2.9 \\
\hline Re-attempt & 1029 & 27.8 \\
\hline \multicolumn{3}{|l|}{ Occupation } \\
\hline Unemployed & 1358 & 36.7 \\
\hline Employed (including student) & 1420 & 38.4 \\
\hline Housewife & 920 & 24.9 \\
\hline \multicolumn{3}{|l|}{ Living condition } \\
\hline No family & 544 & 14.7 \\
\hline Family & 3154 & 85.3 \\
\hline Alcohol co-ingestion & 1554 & 42.0 \\
\hline Previous psychiatric history & 1641 & 44.4 \\
\hline \multicolumn{3}{|l|}{ Suicide attempt method } \\
\hline Poisoning & 2461 & 66.5 \\
\hline Cutting & 904 & 24.4 \\
\hline Drowning & 41 & 1.1 \\
\hline Falling & 96 & 2.6 \\
\hline Hanging & 292 & 7.9 \\
\hline Other methods & 12 & 0.3 \\
\hline Psychiatric interview & 2439 & 66.0 \\
\hline In-hospital mortality & 218 & 5.9 \\
\hline
\end{tabular}

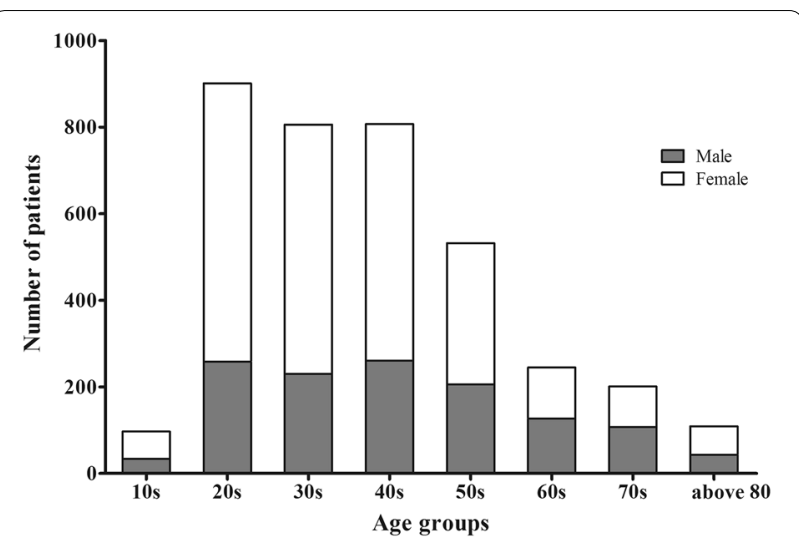

Fig. 1 Number of patients by age group between male and female

by age group. Cuttings account for a larger proportion of younger patients, while the proportion of DSP increases with age. In the case of older adults, the proportion of hanging is higher than that of younger people.

The study population's reasons for suicide attempts are shown in Table 2. Interpersonal relationship issues (51.8\%) were the most common reasons. Of these patients, the most common type of interpersonal relationship issue was couple conflict (32.3\%). Especially, there were significantly differences between the older people and the others in couple conflict. And financial stress was significantly highest in middle aged group $(\mathrm{p}<0.001)$. While that, the physical illness is the most common in the older group significantly $(\mathrm{p}<0.001)$. Among social issues, financial stress was the most common reason for suicide attempts.

Among the patients with repeated suicide attempt $(\mathrm{n}=1029,27.8 \%)$, the incidence of repeated suicide attempt within one, two to three, four to six, and seven to twelve months was $18 \%, 7 \%, 7 \%$ and $20 \%$, respectively. Of the patients who visited the ED due to suicide attempts,

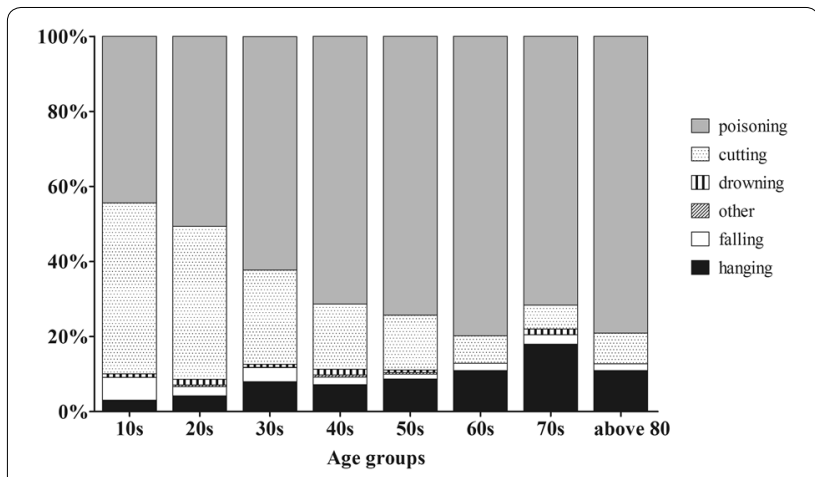

Fig. 2 Suicide methods by age group 
Table 2 Reasons for suicide attempts

\begin{tabular}{|c|c|c|c|c|c|}
\hline Reasons & Total $(\mathrm{N}=3698)$ & Older $(\mathrm{N}=412)$ & $\begin{array}{l}\text { Middle aged } \\
(\mathrm{N}=1777)\end{array}$ & Young $(\mathrm{N}=1509)$ & $p$ \\
\hline \multicolumn{6}{|l|}{ Interpersonal relationship issues } \\
\hline a. Couple conflicts & $1193(32.3)$ & $55(13.3)$ & $621(34.9)$ & $517(34.3)$ & $<0.001$ \\
\hline b. Family conflicts & $548(14.8)$ & $57(13.8)$ & $268(15.1)$ & $223(14.8)$ & 0.813 \\
\hline c. Others & $175(4.7)$ & $9(2.2)$ & $77(4.3)$ & $89(5.9)$ & 0.004 \\
\hline \multicolumn{6}{|l|}{ Social issues } \\
\hline a. Job loss & $87(2.4)$ & $8(1.9)$ & $33(1.9)$ & $46(3.0)$ & 0.068 \\
\hline b. Financial stress & $499(13.5)$ & $35(8.5)$ & $323(18.2)$ & $141(9.3)$ & $<0.001$ \\
\hline c. Work stress & $170(4.6)$ & $0(0.0)$ & $67(3.8)$ & $103(6.8)$ & $<0.001$ \\
\hline d. Legal academic stress & $42(1.1)$ & $3(0.7)$ & $27(1.5)$ & $12(0.8)$ & 0.106 \\
\hline \multicolumn{6}{|l|}{ Psychiatric illness } \\
\hline a. Mood disorder: depressive, bipolar & $356(9.6)$ & $39(9.5)$ & $156(8.8)$ & $161(10.7)$ & 0.186 \\
\hline b. Adjustment disorder & $3(0.1)$ & $0(0.0)$ & $2(0.1)$ & $1(0.1)$ & 0.744 \\
\hline c. Schizophrenia, other psychotic dis & $119(3.2)$ & $7(1.7)$ & $55(3.1)$ & $57(3.8)$ & 0.098 \\
\hline d. Anxiety disorder & $16(0.4)$ & $1(0.2)$ & $9(0.5)$ & $6(0.4)$ & 0.736 \\
\hline e. Panic disorder & $14(0.4)$ & $0(0.0)$ & $5(0.3)$ & $9(0.6)$ & 0.142 \\
\hline f. Substance-related & $83(2.2)$ & $10(2.4)$ & $54(3.0)$ & $19(1.3)$ & 0.003 \\
\hline g. Personality disorder & $31(0.8)$ & $1(0.2)$ & $6(0.3)$ & $24(1.6)$ & $<0.001$ \\
\hline \multicolumn{6}{|l|}{ Physical illness } \\
\hline a. Oneself & $275(7.4)$ & $149(36.2)$ & $107(6.0)$ & $19(1.3)$ & $<0.001$ \\
\hline b. Others & $68(1.8)$ & $22(5.3)$ & $34(1.9)$ & $12(0.8)$ & $<0.001$ \\
\hline \multicolumn{6}{|l|}{ Death of acquaintance } \\
\hline a. Spouse & $28(0.8)$ & $17(4.1)$ & $9(0.5)$ & $2(0.1)$ & $<0.001$ \\
\hline b. Family & $54(1.5)$ & $4(1.0)$ & $23(1.3)$ & $27(1.8)$ & 0.339 \\
\hline c. Others & $18(0.5)$ & $0(0.0)$ & $8(0.5)$ & $10(0.7)$ & 0.220 \\
\hline
\end{tabular}

Parentheses indicate percentage

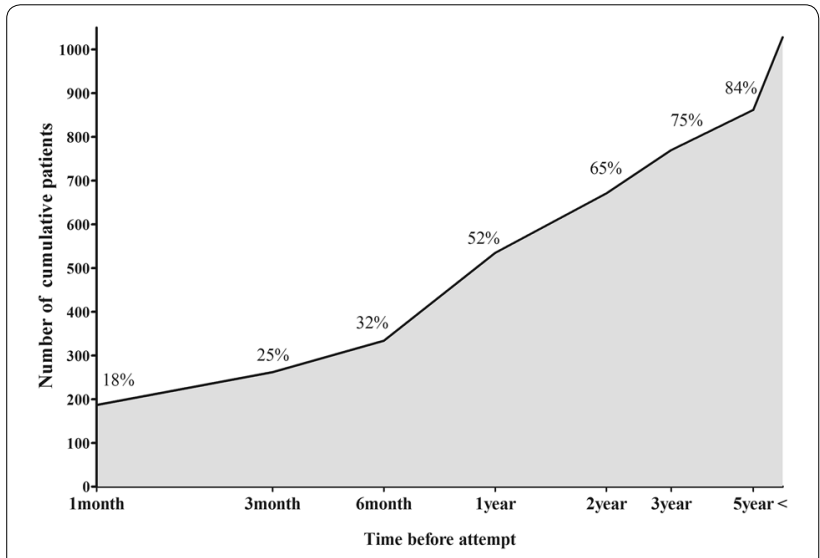

Fig. 3 The incidence of repeated suicide attempt time

$52 \%$ of the patients repeated suicide attempt within one year (Fig. 3).

The previous suicide attempt methods used by the patients with repeated suicide attempts are shown in Table 3. The common previous suicide attempt method was DSP (48.4\%) and cutting (40.1\%). Attempted suicide methods were likely to use previous attempted methods. In the DSP group $(n=659)$, the most common previously used method was DSP $(\mathrm{n}=502,62.8 \%)$, and the second most common was cutting $(n=214,26.8 \%)$. In the cutting group $(\mathrm{n}=306)$, the most common previously used method was cutting $(\mathrm{n}=249,72.8 \%)$, and the second most common was DSP $(n=64,18.7 \%)$. But in critical methods, such as drowning, falling and hanging, Cutting and DSP have been attempt more before than using the same previous method.

Table 4 shows the results of comparing the factors related to suicide attempts by distinguishing young, middle aged adults from older people. Gender, suicide re-attempt, occupation, alcohol co-ingestion, previous psychiatric history, and methods of suicide attempt were significantly different among the groups $(\mathrm{p}<0.001)$. Hanging was the most common suicide method in the older group ( $14.8 \%$ vs. $8.0 \%, 5.9 \%$, respectively), while cutting was the most in young people. And the hospital death rate was significantly higher in older patients than the young and middle aged group $(\mathrm{p}<0.001)$. 
Table 3 The previous suicide attempt methods used by the patients with repeated suicide attempts

\begin{tabular}{lcccccc}
\hline Re-attempt method $(\mathbf{N}=1029)$ & $\begin{array}{l}\text { Poisoning } \\
\mathbf{N}=\mathbf{6 5 9}\end{array}$ & $\begin{array}{c}\text { Cutting } \\
\mathbf{N}=\mathbf{3 0 6}\end{array}$ & $\begin{array}{l}\text { Drowning } \\
\mathbf{N}=\mathbf{5}\end{array}$ & $\begin{array}{l}\text { Falling } \\
\mathbf{N}=\mathbf{1 9}\end{array}$ & $\begin{array}{l}\text { Hanging } \\
\mathbf{N}=\mathbf{3 6}\end{array}$ & $\begin{array}{l}\text { Others } \\
\mathbf{N}=\mathbf{4}\end{array}$ \\
\hline Previous methods & & & & & \\
$\quad$ Poisoning $(n=593,48.4 \%)$ & $502(62.8)$ & $64(18.7)$ & $1(16.7)$ & $5(19.2)$ & $20(41.7)$ \\
Cutting $(n=492,40.1 \%)$ & $214(26.8)$ & $249(72.8)$ & $4(66.7)$ & $12(46.2)$ & $12(25.0)$ & $1(25.0)$ \\
Drowning $(n=12,1.0 \%)$ & $8(1.0)$ & $3(0.9)$ & $0(0.0)$ & $1(3.8)$ & $0(0.0)$ & $0(0.0)$ \\
Falling $(n=37,3.0 \%)$ & $20(2.5)$ & $9(2.6)$ & $1(16.7)$ & $4(15.4)$ & $3(6.3)$ & $0(0.0)$ \\
Hanging $(n=77,6.3 \%)$ & $48(6.0)$ & $13(3.8)$ & $0(0.0)$ & $4(15.4)$ & $12(25.0)$ & $0(0.0)$ \\
Other $(n=15,1.2 \%)$ & $8(1.0)$ & $4(1.2)$ & $0(0.0)$ & $0(0.0)$ & $1(2.1)$ & $2(50.0)$ \\
\hline
\end{tabular}

Parentheses indicate percentage

Table 4 Comparison of characteristics between young, middle aged and older people groups. $(\mathrm{N}=3698)$

\begin{tabular}{|c|c|c|c|c|}
\hline & $\begin{array}{l}\text { Older } \\
n=412\end{array}$ & $\begin{array}{l}\text { Middle aged } \\
\mathrm{n}=1777\end{array}$ & $\begin{array}{l}\text { Young } \\
n=1509\end{array}$ & $p$ \\
\hline Gender & & & & $<0.001$ \\
\hline Male & $207(50.2)$ & $626(35.2)$ & $433(28.7)$ & \\
\hline Female & $205(49.8)$ & $1151(64.8)$ & $1076(71.3)$ & \\
\hline Age, mean SD & $75.2 \pm 6.8$ & $47.5 \pm 7.5$ & $26.7 \pm 5.0$ & $<0.001$ \\
\hline Re-attempt & $55(13.3)$ & $433(24.4)$ & $541(35.9)$ & $<0.001$ \\
\hline Occupation & & & & $<0.001$ \\
\hline Unemployed & $329(79.9)$ & $411(23.1)$ & $618(41.0)$ & \\
\hline Employed(including student) & $34(8.3)$ & $669(37.6)$ & $717(47.5)$ & \\
\hline Housewife & 49 (11.9) & $697(39.2)$ & $174(11.5)$ & \\
\hline Living condition & & & & 0.860 \\
\hline No family & $57(13.8)$ & $262(14.7)$ & $225(14.9)$ & \\
\hline Family & $355(86.2)$ & $1515(85.3)$ & $1284(85.1)$ & \\
\hline Alcohol co-ingestion & $88(21.4)$ & $819(46.1)$ & $647(42.9)$ & $<0.001$ \\
\hline Previous psychiatric history & $130(31.6)$ & $778(43.8)$ & $733(48.6)$ & $<0.001$ \\
\hline \multicolumn{5}{|l|}{ Suicide attempt method } \\
\hline Poisoning & $314(76.2)$ & $1312(73.8)$ & $835(55.3)$ & $<0.001$ \\
\hline Cutting & $30(7.3)$ & $293(16.5)$ & $581(38.5)$ & $<0.001$ \\
\hline Drowning & $3(0.7)$ & $21(1.2)$ & $17(1.1)$ & 0.728 \\
\hline Falling & $8(1.9)$ & $36(2.0)$ & $52(3.4)$ & 0.026 \\
\hline Hanging & $61(14.8)$ & $142(8.0)$ & $89(5.9)$ & $<0.001$ \\
\hline Other methods & $0(0.0)$ & $8(0.5)$ & $4(0.3)$ & 0.305 \\
\hline Psychiatric interview & $271(65.8)$ & 1199 (67.5) & $969(64.2)$ & 0.145 \\
\hline In-hospital mortality & $73(17.7)$ & $93(5.2)$ & $52(3.4)$ & $<0.001$ \\
\hline
\end{tabular}

Parentheses indicate percentage

In multivariate regression analysis revealed a significant association between re-attempts and age groups (aOR: 3.04 and 1.77, young and middle aged group compared with older group, respectively) and a previous psychiatric history (OR: 5.65, 95\% CI 4.79-6.66, $\mathrm{p}<0.001$ ) (Table 5).

\section{Discussion}

In the present study, we sought to summarize detailed characteristics of attempted suicide according to age and methods of suicide attempts. The general findings of the patients who presented to our ED after attempted suicide were as follows: attempted suicide was more prevalent 
Table 5 Univariate and multivariate logistic regression analysis for predicting re-attempt events

\begin{tabular}{|c|c|c|c|c|}
\hline & \multicolumn{2}{|l|}{ Univariate } & \multicolumn{2}{|l|}{ Multivariate } \\
\hline & OR $(95 \% \mathrm{Cl})$ & $\mathrm{p}$ & aOR $(95 \% \mathrm{Cl})$ & $\mathrm{p}$ \\
\hline Female & $1.53(1.31-1.80)$ & $<0.001$ & $1.15(0.97-1.37)$ & 0.106 \\
\hline \multicolumn{5}{|l|}{ Age group } \\
\hline Young people & $3.63(2.68-4.91)$ & $<0.001$ & $3.04(2.21-4.19)$ & $<0.001$ \\
\hline Middle aged people & $2.09(1.54-2.83)$ & $<0.001$ & $1.77(1.28-2.44)$ & $<0.001$ \\
\hline Older people & Reference & & & \\
\hline Unemployed & $1.02(0.88-1.18)$ & 0.754 & & \\
\hline Living without family & $1.17(0.96-1.43)$ & 0.106 & & \\
\hline Previous psychiatric history & $5.89(5.01-6.92)$ & $<0.001$ & $5.65(4.79-6.66)$ & $<0.001$ \\
\hline \multicolumn{5}{|l|}{ Suicide attempt method } \\
\hline Poisoning & $0.92(0.75-1.12)$ & 0.423 & & \\
\hline Cutting & $0.92(0.74-1.14)$ & 0.456 & & \\
\hline Drowning & $0.23(0.30-1.82)$ & 0.166 & & \\
\hline Falling & $1.41(0.71-2.78)$ & 0.321 & & \\
\hline Hanging & $1.03(0.63-1.71)$ & 0.883 & & \\
\hline
\end{tabular}

$O R$ odds ratio, $\mathrm{Cl}$ confidence interval, aOR adjusted odds ratio

in females (especially in young adults), the most common method of attempted suicide was deliberate selfpoisoning, repeated suicide attempts were noted in $27.8 \%$ (of which $52 \%$ were within one year), and interpersonal relationship issues $(51.8 \%)$ were the most common reasons (physical illness was most common reason in older individuals).

Regarding gender differences, women attempted suicide more frequently than men. However, the suicide attempt rates do not differ among people who are 65 years or older; this result consistent with previous findings [14]. Regarding the methods of suicide attempt, DSP was the most common in all ages as described in previous studies $[15,16]$. The higher the age, the higher the rate of attempting suicide with DSP. In contrast, the younger the age, the more often the suicide attempt was made by cutting.

Among patients presenting with suicide attempts, the incidence of a previous suicide attempt was $27.8 \%$ (Table 1), and approximately $14.5 \%$ of patients who attempt suicide make a second attempt during the following year. These findings are similar to the findings of a previous report [17]. Respectively, in the case of poisoning, $62.8 \%$ and in the case of cutting, $72.8 \%$ attempted suicide attempt by the same method. Only $5.8 \%$ of patients with a previous suicide attempt that involved cutting re-attempted suicide by hanging, drowning, and falling. However, these methods are less common but are classified as high lethality methods and have a high risk of completed suicide $[18,19]$. In addition, a large proportion of patients who attempted suicide by cutting are discharged without undergoing a psychiatric interview because they do not wait for a psychiatric consultation after their wounds have been treated [20]. According to a report by Hickey et al., patients who have not received a psychiatric assessment may be at a greater risk of further attempted suicide and completed suicide compared with patients who undergo psychiatric assessment [21]. Therefore, a multidisciplinary team that includes a psychiatrist should assess patients who visit an ED after an attempted suicide by cutting.

Interpersonal relationship issues, especially couple conflicts were the most common cause of suicide attempt in young and middle aged people, while physical illness was cited as the most common reason in older people. And in meddle aged people the financial stress was revealed the more reason of suicide compared the other groups. This shows that different age groups have different reasons for suicide attempts, so it is thought that access to patients who have visited the hospital for suicide attempt be different. For example, it would be helpful for middle aged people to come up with measures for socioeconomic support, while for older people, policies such as continuing mental support through psychiatric connections will be needed to prevent depression in patients who are physically ill. Issues surrounding physical illnesses, such as physical symptom burden, functional disability, social effects of a handicap, and receiving a diagnosis of critical illness, have been repeatedly reported to be associated with suicidal thoughts and behaviors [22-24]. Physical illness has been assumed to be a strong risk factor for older adults suicide in previous studies, and its association with suicide ideation and attempts remained significant even after correction for mental illness as its likely 
consequence [25-27]. Although psychological aspects are important in the treatment of suicide patients, more attention should be paid to the underlying physical causes of attempted suicide especially in older adults. To prevent suicide attempts in the older population, we must actively investigate suicidal thoughts and depression in patients with physical illnesses in the primary care settings.

Comparing young adults and older patients, differences in gender, suicide re-attempt, alcohol co-ingestion, previous psychiatric history, methods of suicide attempts and outcomes are noted. Regarding outcomes, the mortality rate of older patients after admission was significantly higher than that of young adults. This finding might be partially explained not only by their higher physical vulnerability but also by their higher suicide intent. According to a report by Kato et al., older patients are less likely to be found and rescued compared with young adults, possibly leading to serious medical conditions and resulting in a higher risk of death and longer stay in the hospital, particularly in the ICU [28]. In addition, our results show that significantly more patients in the older group had attempted suicide by high lethality methods, such as hanging. Therefore, to prevent suicide attempts or suicide of the older adults, it is important for the primary care physician to identify the suicidal ideation, and psychiatric treatment should be immediately provided. As the results of the screening program for depression in the older adults showed that suicide was effectively reduced, a social system that can recognize the risk factors of suicide attempt or suicide seems to be important [29].

In this study, the previous psychiatric history was the most powerful risk factor for re-attempts. And the younger the patients compared to the older patients, the more likely they were to re-attempts. However, the previous suicide attempt method was not associated with reattempts. These results will help us to find an adequate suicide prevention strategy.

There are several limitations to our study. First, the data are restricted to two tertiary hospitals in Seoul and Gyeongido, South Korea. This region may not be representative of the entire country. Furthermore, patients who re-attempt suicide may have visited another hospital for a previous attempt. Multicenter trials are needed to identify more generalizable risk factors and acquire more accurate data. Second, several known risk factors associated with attempted suicide could not be obtained; certain factors could be more specific. Alcohol dependence, low socioeconomic status, low educational level, unmarried status, traumatic or abusive experiences during childhood, and emotions (i.e., intense feelings of despair, the loss of one's sense of social relevance and the meaning of one's existence) are all risk factors for suicide attempt and re-attempts [30-32]. And this study was cross-sectional analysis, so does not allow drawing causal conclusions. These factors should be evaluated in further studies.

Nevertheless, this study included large samples considering the population of the city and the study period, so the data are expected to reveal some degree of suicide attempts in the region. Prospective cohort design studies are needed to minimize participant loss and study various factors.

\section{Conclusion}

This study attempted to provide information on the characteristics of adult suicide attempters in South Korea. Knowledge of the risk factors associated with attempted suicide can help identify the populations who are exposed to injury or death by suicide attempts. Findings from this study indicate that people who attempt suicide may have different sociodemographic and clinical factors depending on age group. In particular, the reason and method for attempting suicide in the older people were quite different compared with young or middle aged people. Thus, a tailored suicide intervention program for each age group is needed. In future studies, it is necessary to examine the effects of interventions that target these risk factors to reduce attempted suicide and suicide.

\section{Abbreviations \\ ED: Emergency department; DSP: Deliberate self-poisoning; OECD: Organiza- tion for Economic Co-Operation and Development; NEDIS: National Emer- gency Department Information System.}

\section{Authors' contributions}

SHK contributed to the study design, data interpretation, and writing of the manuscript. HJK contributed to the study conception, primary investigator role, and revising of the manuscript. SHO and KC contributed to patient enrollment, statistical analysis, and helped to draft the manuscript. All authors read and approved the final manuscript.

\section{Funding}

Not applicable.

\section{Availability of data and materials}

The datasets used and/or analysed during the current study are available from the corresponding author on reasonable request.

\section{Ethics approval and consent to participate}

The institutional review board of The Catholic University of Korea, Seoul Saint Mary's Hospital approved the study protocols prior to data analysis. Informed consent was waived given the retrospective nature of the study.

\section{Consent for publication \\ Not applicable.}

\section{Competing interests}

The authors declare that they have no competing interests.

\section{Author details}

${ }^{1}$ Department of Emergency Medicine, Eunpyeong St. Mary's Hospital, College of Medicine, The Catholic University of Korea, Seoul, Republic of Korea. ${ }^{2}$ Department of Emergency Medicine, Seoul St. Mary's Hospital, College of Medicine, The Catholic University of Korea, 222 Banpo-daero, Seocho-gu, 
Seoul 06591, Republic of Korea. ${ }^{3}$ Department of Emergency Medicine, St. Vincent's Hospital, College of Medicine, The Catholic University of Korea, Suwon, Gyeonggi-do, Republic of Korea.

Received: 28 July 2019 Accepted: 15 June 2020

Published online: 22 June 2020

\section{References}

1. WHO. Preventing suicide: A global imperative. http://www.who.int/ mental_health/suicide-prevention/world_report_2014/en/. Accessed 11 July 2018.

2. WHO. WHO releases guidance on responsible reporting on suicide. http://www.who.int/gho/mental_health/suicide_rates/en/. Accessed 18 July 2018.

3. OECD. Suicide rates (indicator). https://doi.org/10.1787/a82f3459-en. Accessed 7 Nov 2018

4. Park S, Lee HB, Lee SY, Lee GE, Ahn MH, Yi KK, et al. Trends in suicide methods and rates among older adults in South Korea: a comparison with Japan. Psychiatry Investig. 2016;13(2):184-9.

5. Korea S. Future population projection. http://www.kostat.go.kr/portal/ korea/index.action. Accessed 3 June 2018.

6. Kuo CJ, Gunnell D, Chen CC, Yip PS, Chen YY. Suicide and nonsuicide mortality after self-harm in Taipei City, Taiwan. Br J Psychiatry. 2012;200(5):405-11.

7. Hawton K, Bergen H, Cooper J, Turnbull P, Waters K, Ness J, et al. Suicide following self-harm: findings from the Multicentre Study of self-harm in England, 2000-2012. J Affect Disord. 2015;175:147-51.

8. Fedyszyn IE, Erlangsen A, Hjorthoj C, Madsen T, Nordentoft M. Repeated suicide attempts and suicide among individuals with a first Emergency Department contact for attempted suicide: a Prospective, Nationwide, Danish Register-Based Study. J Clin Psychiatry. 2016;77(6):832-40.

9. Tidemalm D, Beckman K, Dahlin M, Vaez M, Lichtenstein P, Langstrom N, et al. Age-specific suicide mortality following non-fatal self-harm: national cohort study in Sweden. Psychol Med. 2015;45(8):1699-707.

10. Gibb SJ, Beautrais AL, Fergusson DM. Mortality and further suicidal behaviour after an index suicide attempt: a 10-year study. Aust N Z J Psychiatry. 2005;39(1-2):95-100.

11. Chen VC, Tan HK, Chen CY, Chen TH, Liao LR, Lee CT, et al. Mortality and suicide after self-harm: community cohort study in Taiwan. Br J Psychiatry. 2011;198(1):31-6.

12. Schoenbaum M, Kessler RC, Gilman SE, Colpe LJ, Heeringa SG, Stein $\mathrm{MB}$, et al. Predictors of suicide and accident death in the Army Study to Assess Risk and Resilience in Servicemembers (Army STARRS): results from the Army Study to Assess Risk and Resilience in Service members (Army STARRS). JAMA Psychiatry. 2014;71(5):493-503.

13. Franklin JC, Ribeiro JD, Fox KR, Bentley KH, Kleiman EM, Huang X, et al. Risk factors for suicidal thoughts and behaviors: a meta-analysis of 50 years of research. Psychol Bull. 2017;143(2):187-232.

14. Draper BM. Suicidal behaviour and suicide prevention in later life. Maturitas. 2014;79(2):179-83.

15. Prescott K, Stratton R, Freyer A, Hall I, Le Jeune I. Detailed analyses of selfpoisoning episodes presenting to a large regional teaching hospital in the UK. Br J Clin Pharmacol. 2009;68(2):260-8.

16. Hendrix L, Verelst S, Desruelles D, Gillet JB. Deliberate self-poisoning: characteristics of patients and impact on the emergency department of a large university hospital. Emerg Med J. 2013;30(1):e9.
17. Carroll R, Metcalfe C, Gunnell D. Hospital management of self-harm patients and risk of repetition: systematic review and meta-analysis. J Affect Disord. 2014;168:476-83.

18. Runeson B, Tidemalm D, Dahlin M, Lichtenstein P, Langstrom N. Method of attempted suicide as predictor of subsequent successful suicide: national long term cohort study. BMJ. 2010;341:c3222.

19. Schmidtke A, Bille-Brahe U, DeLeo D, Kerkhof A, Bjerke T, Crepet P, et al. Attempted suicide in Europe: rates, trends and sociodemographic characteristics of suicide attempters during the period 1989-1992. Results of the WHO/EURO Multicentre Study on Parasuicide. Acta Psychiatr Scand. 1996;93(5):327-38.

20. Kim J, Kim HJ, Kim SH, Oh SH, Park KN. Analysis of deliberate self-wristcutting episodes presenting to the Emergency Department. Crisis. 2016;37(2):155-60

21. Hickey L, Hawton K, Fagg J, Weitzel H. Deliberate self-harm patients who leave the accident and emergency department without a psychiatric assessment: a neglected population at risk of suicide. J Psychosom Res. 2001;50(2):87-93.

22. Fang F, Fall K, Mittleman MA, Sparen P, Ye W, Adami HO, et al. Suicide and cardiovascular death after a cancer diagnosis. N Engl J Med. 2012;366(14):1310-8

23. Fassberg MM, Cheung G, Canetto SS, Erlangsen A, Lapierre S, Lindner $\mathrm{R}$, et al. A systematic review of physical illness, functional disability, and suicidal behaviour among older adults. Aging Ment Health. 2016;20(2):166-94.

24. Walker J, Waters RA, Murray G, Swanson H, Hibberd CJ, Rush RW, et al. Better off dead: suicidal thoughts in cancer patients. J Clin Oncol. 2008;26(29):4725-30

25. Kim YR, Choi KH, Oh Y, Lee HK, Kweon YS, Lee CT, et al. Elderly suicide attempters by self-poisoning in Korea. Int Psychogeriatr. 2011:23(6):979-85.

26. Innamorati M, Pompili M, Di Vittorio C, Baratta S, Masotti V, Badaracco A, et al. Suicide in the old elderly: results from one Italian county. Am J Geriatr Psychiatry. 2014;22(11):1158-67.

27. Ratcliffe GE, Enns MW, Belik SL, Sareen J. Chronic pain conditions and suicidal ideation and suicide attempts: an epidemiologic perspective. Clin J Pain. 2008;24(3):204-10

28. Kato K, Akama F, Yamada K, Maehara M, Saito M, Kimoto K, et al. Frequency and clinical features of suicide attempts in elderly patients in Japan. Psychiatry Clin Neurosci. 2013;67(2):119-22.

29. Oyama H, Sakashita T. Long-term effects of a screening intervention for depression on suicide rates among Japanese Community-dwelling older adults. Am J Geriatr Psychiatry. 2016;24(4):287-96.

30. Mendez-Bustos P, de Leon-Martinez V, Miret M, Baca-Garcia E, Lopez-Castroman J. Suicide reattempters: a systematic review. Harv Rev Psychiatry. 2013;21(6):281-95.

31. Minayo MC, Cavalcante FG. Suicide attempts among the elderly: a review of the literature (2002/2013). Cien Saude Colet. 2015;20(6):1751-62.

32. Finkelstein $Y$, Macdonald EM, Hollands S, Sivilotti ML, Hutson JR, Mamdani MM, et al. Repetition of intentional drug overdose: a population-based study. Clin Toxicol. 2016;54(7):585-9.

\section{Publisher's Note}

Springer Nature remains neutral with regard to jurisdictional claims in published maps and institutional affiliations. 